\title{
Qual (que) é a parte da Linguística que estuda a heterogeneidade da linguagem humana?
}

Which part of Linguistics studies the heterogeneity of human language?

\author{
Maria Cecilia Mollica \\ UFRJ/CNPq/FAPERJ/IBICT \\ Samara Moura \\ PIBIC/UFRJ \\ Thaís Pedretti Lofeudo \\ IC/CNPq/UFRJ
}

\section{Resumo}

Neste texto, estudo a variação das interrogativas-Q, com a finalidade de verificar o efeito do emprego de algumas variáveis com e sem clivagem nessas construções em português. Lanço mão também de estudo em painel e em tendência para verificar se o processo variável encontra-se em mudança na língua. Os resultados demonstram que há mudança nos indivíduos, e não na comunidade, desde que haja progresso na escolarização dos sujeitos. O estudo visa, em última análise, demonstrar como são aplicados os pressupostos teóricos e metodológicos em pesquisa Sociolinguística.

\section{Palavras-chave}

Interrogativas-Q, Relevância do Letramento, Pesquisa em tempo real, Painel, Tendência, Análise multivariacional. 


\section{Abstract}

This paper analyzes the variation of Q-interrogatives in Portuguese in order to verify the effect of the use of some variables with and without cleavage in these constructions. The analysis includes real time research panel and trend analysis to investigate if the process variable is changing in the language. The results indicate that there is change at the individual level, but not in the community, provided there is progress in the formal education of the subjects. The study also aims to demonstrate how theoretical and methodological tools are applied to the field of Sociolinguistic research.

\section{Keywords}

Q-interrogatives, Importance of literacy, Real-time research, Panel and trend analysis, Multivariacional description. 


\section{Introdução}

forma de interrogar em português tem sido tratada, pela tradição
gramatical, no capítulo dedicado aos pronomes interrogativos em que
se arrolam as categorias gramaticais que têm tal função nas sentenças. Segundo Rocha Lima (2006), os pronomes interrogativos são os pronomes indefinidos quando empregados em frases interrogativas. Há a interrogação direta, em sentenças terminadas por interrogação e as indiretas cuja sentença termina por um ponto.

Perini (2010, p. 124) distingue construções interrogativas fechadas (sim/ não), como em (1) Você já terminou a faxina?, das construçôes interrogativas abertas (interrogativas-Q), tal como exemplificado em (2) Qual aparelho você vai levar?, em que o interrogativo funciona como um SN ou um SADV e pode constituir sozinho esse SN (precedido ou não de preposição), como em: (3) Quem te ajudou?, (4) De onde apareceu esse sujeito?, (5) Você está trabalhando em qual seção?

Completa Perini que as interrogativas abertas podem ser complementadas por é que ou foi que, como estratégia de constituição de clivagem: (6) quem foi que perdeu o ano? Ainda de acordo com Perini, há casos em que a presença de $e$ que é obrigatória: (7) o que é que você arrumou, em que é que ainda pode reduzirse a apenas que, como em (8) o que que você está lendo?

O denominado Parâmetro-Q, segundo a Teoria da Gramática, distingue línguas como o Inglês do Japonês, pelo fato de os constituintes interrogativos se moverem ou não se moverem na sintaxe das línguas. As interrogativas-Q podem aparecer na periferia à esquerda ou à direita, no final da sentença, recebendo a denominação de qu-in situ (GROLLA, 2000; SILVEIRA, 2011). De acordo com Faria et al (1996, p. 290), “o Inglês fixa o valor positivo para este parâmetro, enquanto o Japonês fixa o negativo. $\mathrm{O}$ português e as Línguas Românicas fixam positivamente o parâmetro tal como o Inglês." Logo, o Inglês e as línguas românicas manifestarão o elemento-QU à esquerda, ao passo que o 
Japonês manifestará tal elmento à direita, na posição in situ. Algo que diferencia o Inglês de línguas românicas como o português brasileiro (PB) é que nestas tanto o movimento-QU quanto o QU in situ são permitidos.

Kato e Raposo (1996) consideram (8) um tipo de estrutura QU de clivagem com apagamento de cópula. Braga, Kato e Mioto (2009) estudaram esse tipo de construção com evidências na variedade do português brasileiro. Explicam os autores que estruturas como (a) quem que a senhora acha que cuida de toda essa parte...? (DID SP); (b) qual que seria o material? (DID SSA) (c) por que que a senhora gostou dessa peça? (DID SP); (d) você sabe o que que é UPC? (D2 RJ) ainda podem ter uma expressão- $Q$ na periferia esquerda da sentença, adicionada pelo complementizador, formando o fenômeno de ComP duplamente preenchido. Ou seja, o pronome ocupa a posição de especificador de CP e o complementizador ocupa a posição de núcleo.

Alexandre (2006) defende a tese de que as interrogativas-Q são predominantes no português falado em Cabo Verde, caracterizando uma estratégia de focalização obrigatória tanto quanto na sintaxe do crioulo português falado na Guiné Bissau. Tal afirmação se torna um tanto abalada, uma vez que as variedades do português brasileiro e do português europeu também exibem interrogativas com clivagem, seja na posição inicial da sentença (periferia à esquerda), seja em posição final (qu-in-situ), quer em discurso direto, quer em discurso indireto.

Neste texto, focalizo as interrogativas-Q com e sem clivagem sob a ótica da Sociolinguística, perspectiva ainda não explorada na literatura. Advogo a tese de que o fenômeno deve ser tratado levando em conta suas motivações de uso, valendo-se de modelo que busca investigar o dinamismo dos sistemas linguísticos. Assim, parto do pressuposto de que as interrogativas-Q supōem a existência de um ou de mais de um processo variável.

$O$ foco do estudo se restringe à variação entre qual $X$ e qual que $X$, sendo que

(i) que o marcador de clivagem,

(ii) $X$ o contexto seguinte à construção de interrogação,

(iii) é variável a posição das variantes na sentença.

O objetivo da pesquisa é o de comprovar a sistematicidade dos usos concretos, aparentemente aleatórios, de modo a demonstrar que a Sociolinguística é a área da Linguística que atesta a regularidade de empregos linguísticos dinâmicos. Os pressupostos sociolinguísticos, assim como seus procedimentos 
de análise, permite estimar o grau de implementação da variação em distintas comunidades de fala por meio da descrição sistemática do efeito de restriçōes de natureza estrutural e não estrutural em relação aos processos variáveis constitutivos da contraparte heterogênea das línguas naturais humanas.

\section{Clivagem e multifuncionalidade}

A clivagem tem sido estudada numa perspectiva funcionalista por Braga (mimeo a e b). Nos estudos mencionados, são elencados tipos distintos de construções clivadas e sua funcionalidade. No entanto, a autora não volta atenção para as construções interrogativas variáveis (com e sem clivagem).

Neste artigo, a ênfase consiste exatamente no exame da emergência das variantes interrogativas qual $X$ (sem clivagem) e qual que $X$ (com clivagem) enquanto motivadas e dependentes do contexto. O pressuposto é de que há equivalência semântica entre as formas em competição, seguindo as orientações de Labov (1969; 1972), embora algumas ocorrências possam ter distintas nuanças de sentido.

Os dados do fenômeno variável em exame foram extraídos das amostras PEUL (<www.letras.ufrj.br/peul>).

(9) Qual é o jogador que você gosta mais?

(10) Qual [ruído] que a senhora prefere fazer?

Em (9) e (10), observa-se a alternância de interrogativas-Q sem cópula qual $X$ variando em qual que $X$, muito embora se evidenciem também empregos de qual é que, com o verbo ser presente - ver exemplos (11) e (12).

(11) qual é que período do ano que abre a inscrição, quais são as áreas \{est\}, sei que tá abrindo pra todas as [áreas].”

(12) Quando [“aparece ele é”]- [hes] a última que passou lá- quer dizer, agora, não sei qual é que está, mas, antes dessa, estava [hes] água viva. ["que é linda!"] não é? [est] [“Aqueles"] cenários maravilhosos!

Neste estudo, as estruturas em exame sem a cópula, podendo ou não ter clivagem, ocorrem no início da sentença (periferia à esquerda) e no final (qu-in situ). 


\section{(13) E- Qual é essa melhor maneira?}

(14) Você chegou a pensar qual que é o lugar?

Além disso, a interrogativa- $Q$ pode ser empregada em discurso direto, a exemplo de (13) e em discurso indireto, como em (15) e (16). O ambiente seguinte, aqui representado simbolicamente por $X$, pode ser um $\mathrm{SN}$, tal como em (14), ou um verbo no presente ou no passado, como em (13), (15) e (16).

(15) F- Tem que ter uma turma e boa mesmo, porque se não, não adianta. Conforme outro dia mesmo eu estava vendo [hes] um programa aí- não sei qual foi o programa? Programazinho que eu estava vendo, então o senador lá em São Paulo, Orestes ["Queste"] estava falando que a verba para mordomia do governo de São Paulo é maior do que a que ele tem para trabalhar para o estado.

(16) F- [Nada! É, não] Existe nada! E você sabe qual é a maior nossa clientela aqui?

A literatura atribui à clivagem função de focalização, de realce. Note que também é comum a topicalização do $\mathrm{SN}$ para então a construção interrogativa ocorrer como repetição do referente do $\mathrm{SN}$.

(17) E o outro, qual é o outro? [pequeno silêncio] Não tem algum time que joga futebol legal por aqui? [batidinhas]

Há, por outro lado, estruturas qual é, entendidas aqui como pseudo interrogativas, por terem perdido os traços plenos da interrogação em decorrência de operação de gramaticalicação e de ressemantização. São expressões fixas na língua como em (18).

(18) F- [É.] Necessidade, a gente sempre tem, não é? [est] Mas não é obrigatória, aquela necessidade: "vai trabalhar, se não, [est] qual é? A gente vai passar fome." Não é nada disso. [est] Está entendendo? Necessitar, necessita. Pô, às vezes, a gente quer uma fruta a mais [hes], está me entendendo? [est] Quer um negocinho a mais; às vezes, você tem que fazer um esforçozinho para comprar uma roupa para um, deixar o outro esperando para o próximo mês. 
A expressão qual é, cristalizada, corresponde grosso modo ao significado de "como é que fica?" ou "isso não pode ficar assim". No estudo desenvolvido e mostrado neste artigo, foram retiradas as ocorrências de qual é, de significado e uso mais populares.

Tais construçóes merecem tratamento à parte ainda não devidamente desenvolvido. Eis então que a expressão congelada qual é, de valor vocativo e de conotação negativa, não faz parte da variável dependente definida na pesquisa, de sorte que os dados do tipo (18) e (19) foram então desconsiderados na quantificação.

(19) F- Ele está sabendo que eu não tenho nada a ver com a parada, sabe qual é? [est] Mas aí é o seguinte, eles quer é mais. Aí vai ver [hes]- [muxoxo f]. Eu nem ligo para eles. [est] Ontem mesmo eu fui, bem dizer, lá dentro da área deles.

\section{O processo focalizado, as variáveis independentes e os procedimentos adotados na análise}

A descrição variacionista que empreendemos considera como variável dependente as construçōes interrogativas qual $X$, variando com a clivada correspondente sem cópula qual que $X$ quando ainda estão preservados os traços de interrogação. Lança mão de análise quantitativa laboviana e examina o processo variável em tempo real sob as perspectivas de tendência e de painel, além de utilizar análise de correlação de fatores com resultados por frequência e probabilidades.

As seguintes variáveis independentes não linguísticas foram consideradas: fala do entrevistador e fala do entrevistado, três faixas de escolarização (nível fundamental, nível médio e nível superior). Buscou-se atestar o efeito positivo desses fatores com relação à emergência da variante com clivagem qual que $X$ nos entrevistadores e nos entrevistados, considerando que a variante marcada com clivagem não atende ao cânone da tradição gramatical.

Como variáveis independentes de natureza estrutural, levamos em conta: (a) o movimento das variantes interrogativas em exame (início e final de sentença), (b) a ocorrência das variantes estudadas em discurso direto e indireto e (c) o ambiente seguinte aqui simbolizado $\operatorname{com} X$.

A aposta é a de que o emprego da variante interrogativa qual que $X$ emerge mais quando o pronome é deslocado para o final da sentença, é empregado em 
discurso indireto e é usado por falantes de nível baixo de letramento. Além de ser estratégia de ênfase, a clivagem (ainda que contraditoriamente) cumpre a função de atenuação quando empregada em contexto de discurso indireto. $\mathrm{Na}$ maioria das vezes, possibilita que o falante evite o uso de qual é cristalizado, expressão que pode soar vulgar, confundindo-se com a que assumiu outro sentido na língua.

Nos entrevistadores, a variante qual que $X$, também atenuadora, só é empregada em discurso direto, portanto em posição inicial pré-verbal.

(20) E- E qual é a matéria que você tirava as melhores notas?

Verifica-se também estreita relação entre o emprego de interrogativas- $Q$ com sentenças relativas e o sistema de regência verbal, observado no exemplo (20). Um estudo ampliado, que ainda está por ser desenvolvido, deve considerar a relação entre o sistema interrogativo, as construçóes encaixadas e a transitividade verbal, assim como a ordem dos constituintes.

A pesquisa mostrada neste artigo, no entanto, não discute o intricado quadro que envolve os empregos das interrogativas- $Q$ na arquitetura da gramática da língua portuguesa. A descrição fica nos limites já demarcados, de modo a poder tão somente cumprir os objetivos de:

(a) confirmar motivaçōes de ordem pragmática e cognitiva da variação entre qual $X$ e qual que $X$;

(b) apontar a importância da Sociolinguística como área da Linguística que dá conta de atestar a sistematicidade da variação linguística.

De acordo com Pezzati e Fontes (2007, p. 195),

fenômenos linguísticos podem ser explicados de uma forma psicológica e pragmaticamente adequada dentro de um quadro teórico e metodológico mais amplo, em que expressões linguísticas são vistas como manifestaçôes da intenção do falante e, assim, como fatos da língua em uso. Em outras palavras, um fenômeno tipicamente morfossintático, como a ordenação de constituintes e a ocorrência de clivagem em estruturas de interrogativas-Q, é motivado por fatores de ordem semântica, e principalmente de ordem pragmática, que se refletem na morfossintaxe. 


\section{Estabilidade ou mudança: restrições de emprego de qual que $X$}

Calculados todos os dados das três amostras (Censo 1980, Censo 2000, 17 falantes recontatados da amostra de 1980), a clivagem nas construçôes interrogativas em estudo apresenta percentual em torno de 6\% nos anos 1980 e em 2000. O input da regra se diferencia quando calculamos em separado.

\section{Qual que}

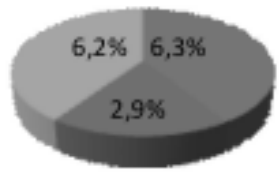

Amostra 1980

Amostra recontactados

Amostra 2000

GRÁFICO I - Distribuição dos percentuais de emprego da variante qual que $X$, segundo os corpora examinados

Pelo GRAF. I, não há diferença de input da regra entre as amostras de 1980 e 2000. No entanto, observa-se um decréscimo significativo no emprego de qual que $X$ nos falantes dos anos 1980 que foram recontatados num espaço de 20 anos, em 2000.

Consideradas conjuntamente, o comportamento das amostras dos anos 1980 e 2000 se mostra similar. Entretanto, num estudo em tempo real, verificase tanto acréscimo quanto decréscimo das interrogativas- $Q$ com clivagem quando controlado o efeito da variável escolarização. A situação em 1980, correlacionada com a escolaridade dos falantes e exibida em percentuais no GRAF. II, evidencia aumento da clivagem nas interrogativas- $Q$ nos menos letrados e decréscimo nos mais letrados. 


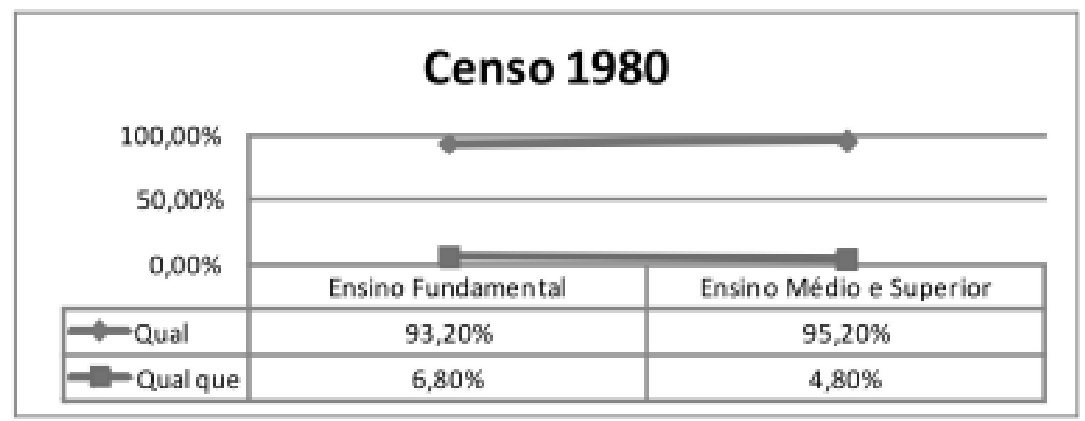

GRÁFICO II - Percentual de ocorrência de clivagem nas interrogativas-Q de acordo com o grau de letramento na amostra Censo 80.

Numa perspectiva trend study (LABOV, 1994), em que se verifica em outra sincronia numa amostra semelhante da sincronia anterior, a tendência é reforçada. Em 2000, 20 anos depois, o efeito da escolarização se torna acentuada, como provam os quantitativos do GRAF. III.

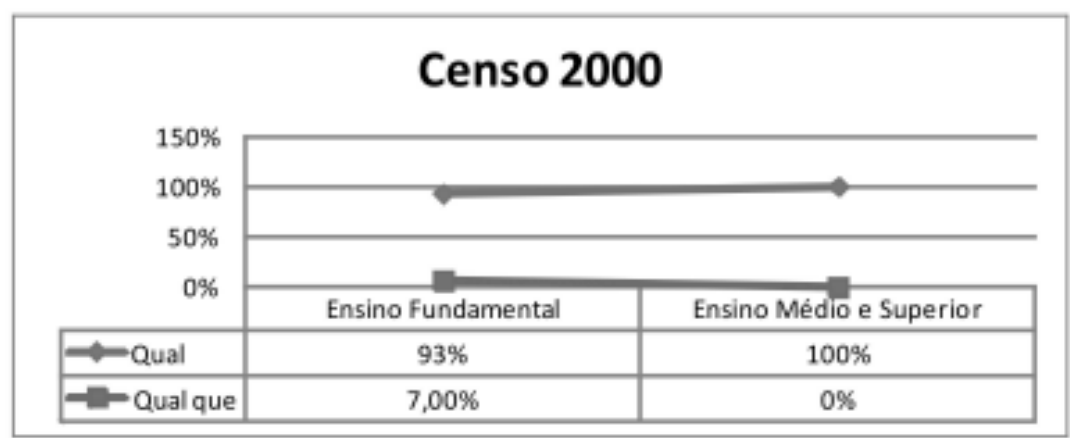

GRÁFICO III - Percentual de ocorrência de clivagem nas interrogativas-Q em relação ao grau de letramento na amostra de 2000: abordagem em tendência.

De fato, o efeito da escolarização se confirma de novo com base nos resultados apontados no GRAF. IV em estudo em painel. O emprego da variante interrogativa-Q com clivagem, nos falantes recontatados da amostra 1980, desaparece nos sujeitos mais escolarizados. 


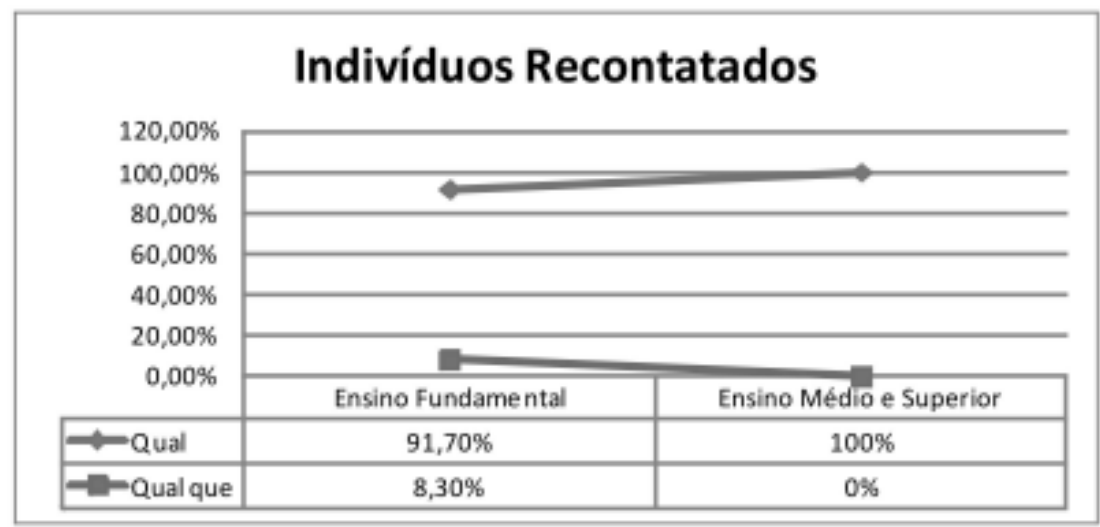

GRÁFICO IV - Percentual de ocorrência de clivagem nas interrogativas-Q em relação ao grau de letramento na amostra 2000: abordagem em painel.

O estudo em painel (ver resultados no GRAF. IV), que consiste na comparação de amostras de fala dos mesmos falantes em diferentes pontos do tempo, permite finalmente captar o movimento de mudança nos indivíduos com relação à regra examinada nesta pesquisa: os falantes em 1980 que se qualificaram e atingiram nível médio ou superior de ensino deixam de usar a variante qual que $X$, confirmando os quantitativos do GRAF. II, relativos à análise em tendência (conferir resultados no GRAF. II). Em contrapartida, os sujeitos que se mantiveram no mesmo patamar de letramento (Fundamental incompleto ou completo) até exibem aumento de emprego da interrogativa-Q com clivagem.

Pode-se concluir, portanto, que a análise em tempo real, por tendência, atesta estabilidade da variação, reafirmando padrão semelhante nas duas sincronias examinadas. A análise por painel, porém, aponta para a existência de mudança em razão do letramento: a escolarização mais alta dos falantes é responsável pelo comportamento dos indivíduos que eliminam o emprego da variante qual que $X$, tal como se confirma também nos percentuais dos entrevistadores, todos de nível universitário (vejam-se os números nas tabelas). Eis a diferença entre mudança no indivíduo e mudança na comunidade. Os resultados obtidos acusam mudança nos indivíduos, e não no sistema da língua.

Além de verificar o fenômeno em tempo real, os dados foram processados pelo Programa Goldvarb X por meio do qual comfirmaram-se as hipóteses postuladas. A escolarização se verifica novamente muito relevante pelos quantitativos mostrados na TAB. I. 
TABELA I

Efeito da escolarização em relação à clivagem nas interrogativas-Q

\begin{tabular}{lccc}
\hline & & $\%$ & Pesos relativos \\
\hline Nível Fundamental & $11 / 140$ & $7.9 \%$ & 0,80 \\
Nível Médio e Superior & $1 / 52$ & $1,9 \%$ & 0.20 \\
\hline
\end{tabular}

A análise multivariacional revela as frequências de uso mais altas da variante com clivagem (em desacordo com a norma de prestígio) e boas chances de as interrogativas-Q com clivagem emergirem nos falantes de menor escolarização. Num universo de 192 dados variáveis, alternando a variante qual $X$ com qual que $X$, os sujeitos de letramento até o Nível Fundamental produzem mais a variante interrogativa-Q com clivagem, com chances de 0,80 de probabilidade, comparativamente à tendência baixa de apenas 0,20 de qual que $X$ emergir em falantes de nível Médio e Superior. Esses resultados indicam que a clivagem na interrogação é uma construção não acolhida pela norma de prestígio e vai deixando de ser usada à medida que aumenta a escolaridade dos usuários da língua: de fato, o efeito do letramento é relevante para podar o uso de interrogativas-Q com clivagem.

Verifica-se também que a clivagem na interrogação é barrada, sobretudo em final de sentença, como se pode conferir com base nos resultados mostrados na TAB. II.

\section{TABELA II}

Efeito do lócus sintático na sentença em relação ao emprego da clivagem nas interrogativas- $Q$

\begin{tabular}{lccc}
\hline & & $\%$ & Pesos relativos \\
\hline $\begin{array}{l}\text { Início de sentença } \\
\text { (Periferia à esquerda) }\end{array}$ & $9 / 93$ & $9,7 \%$ & 0.70 \\
$\begin{array}{l}\text { Final de sentença } \\
\text { (qu-in-situ) }\end{array}$ & $1 / 66$ & $1,5 \%$ & 0.30 \\
\hline
\end{tabular}

A TAB. II apresenta cálculos estatísticos em relação a dados de construções interrogativas-Q, com e sem clivagem, correlacionados ao lócus da construção, seja no início de sentença (periferia à esquerda), seja em final da sentença (qu-in-situ), quando há então a interrogação está no extremo oposto da frase. Os números apontam (cf. resultados na TAB. II) que a variante clivada qual que $X$ constitui estratégia de interrogação com chances altas de emprego no início, no lócus sintático não marcado. 
No entanto, razōes de ordem cognitiva e pragmática também atuam. $\mathrm{O}$ tipo de discurso direto e indireto (aqui tratados como sinônimo de interrogação direta e indireta) influi na emergência da interrogativa-Q com clivagem, como se pode inferir pelos números exibidos pela TAB. III.

TABELA III

Efeito do tipo de discurso em relação ao emprego da clivagem nas interrogativas-Q

\begin{tabular}{lccc}
\hline & & $\%$ & Pesos relativos \\
\hline Discurso indireto & $10 / 88$ & $11,4 \%$ & 0,70 \\
Discurso direto & $2 / 104$ & $1,9 \%$ & 0.30 \\
\hline
\end{tabular}

Ainda que o lugar na sentença seja importante (cf. resultados na TAB. II), as ocorrências das interrogativas-Q com clivagem são sensíveis ao discurso, já que a variante qual que $X$ tende a ser empregada em discurso indireto e tem seu uso refreado em discurso direto. Pelos resultados, a variante qual que $X$ apresenta chance baixa (0.30) de emergir em perguntas abertas, exemplo (21), e tende a surgir mais em interrogação indireta $(0,70)$, como no exemplo (22).

(21) Qual que você acha melhor, futebol ou basquete?

(22) E- Qual é a estória? [eu]- eu não vi o filme, não sei qual é a [estória?]

$\mathrm{O}$ ambiente seguinte também constitui vetor importante para a escolha de qual $X$ ou qual que $X$, de acordo com as hipóteses postuladas.

TABELAIV

Efeito do contexto seguinte $X$ em relação ao emprego da clivagem nas interrogativas-Q

\begin{tabular}{cccc}
\hline & & $\%$ & Pesos relativos \\
\hline $\mathrm{X}=\mathrm{SN}$ & $7 / 43$ & $14 \%$ & 0,70 \\
$\mathrm{X}=\mathrm{SV}$ & $5 / 142$ & $3.5 \%$ & 0.40 \\
\hline
\end{tabular}

Como estratégia de focalização, a clivagem tem grandes chances de emprego diante de sintagmas nominais, porque opera a ativação do referente provavelmente disponível no discurso. É de se supor que sejam entidades evocadas e, por meio da clivagem, sejam realçadas e colocadas no foco da consciência.

Note-se que, diante de outros contextos, as estratégias de realce não são propriamente necessárias, tornando-se nulo o emprego da variante qual que $X$. 
O mesmo ocorre para os entrevistadores da década de 1980, como atestam os resultados do GRAF. V.

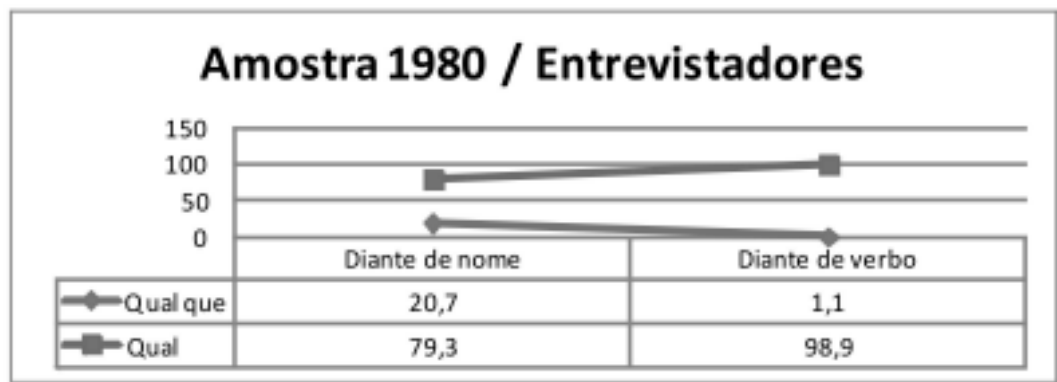

GRÁFICO V - Comportamento da variável contexto seguinte na amostra Censo 1980 nas perguntas dos entrevistadores.

Pelo GRAF. V, há um aumento de focalização no emprego da variante qual $X$ na década de 1980 , indo a um patamar de quase $100 \%$.

O padrão se mantém em 2000, com ligeira elevação para a variante qual que $X$.

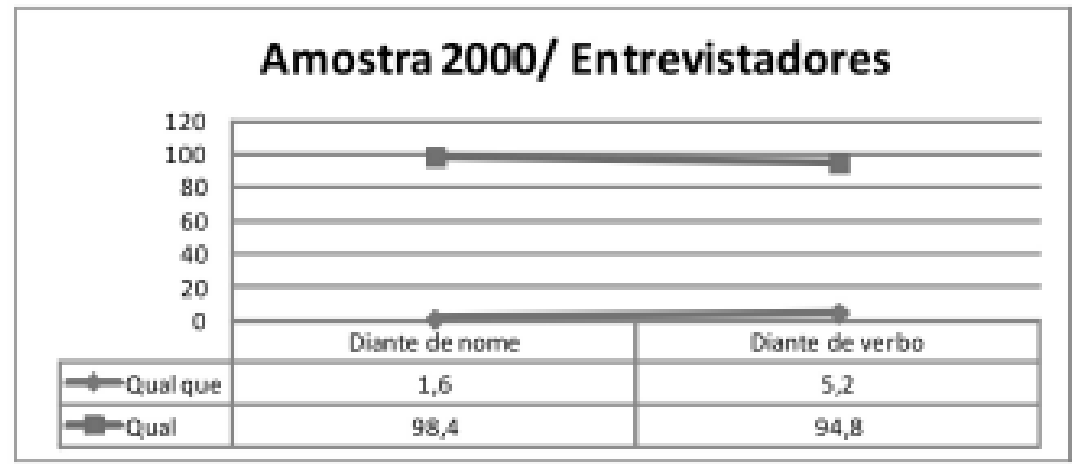

GRÁFICO VI - Comportamento da variável contexto seguinte $X$ na amostra Censo 2000 nas perguntas dos entrevistadores.

Note-se, no entanto, que o tipo de pergunta modifica as tendências refletidas nos GRAF. V e VI. Os entrevistadores não apresentam a variante qual que $X$ nas perguntas diretas (abertas) e aumentam levemente seu uso em discurso indireto. Comparem-se os resultados mostrados nos GRAF. VII e VIII, da década de 1980 e da amostra de 2000, respectivamente. 


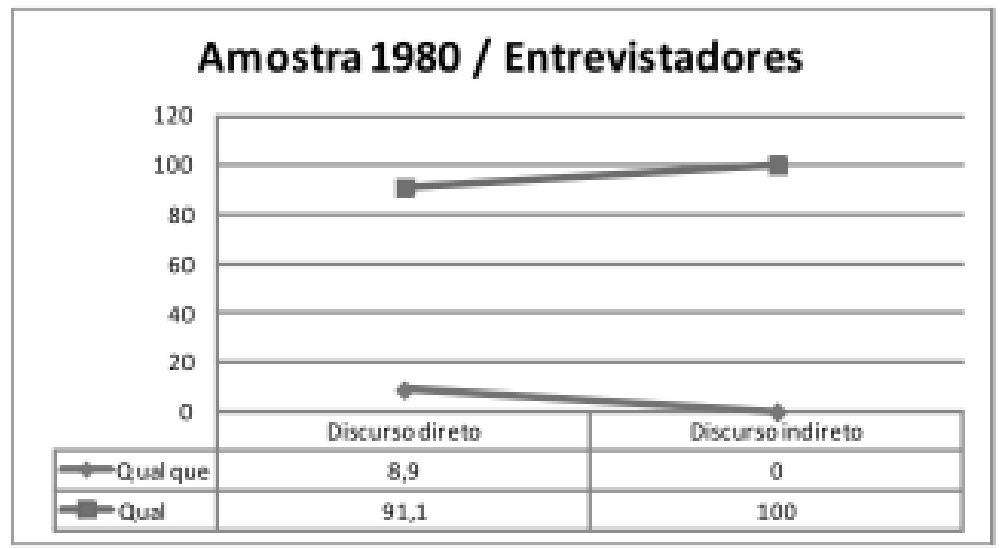

GRÁFICO VII - Comportamento da variável tipo de pergunta na amostra Censo 2000 nas construçóes interrogativas dos entrevistadores.

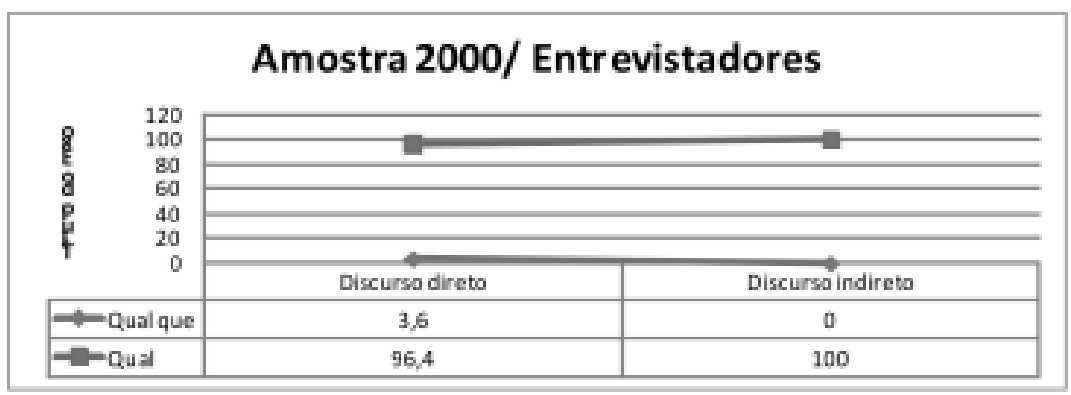

GRÁFICO VIII - Comportamento da variável tipo de pergunta na amostra Censo 2000 nas construçôes interrrogativas dos entrevistadores.

Comparando os resultados exibidos nos GRAF. VII e VIII, é possível supor que a função de focalização da variante qual que $X$ se sobrepõe à ação da variável ambiente seguinte. Em perguntas não abertas, com ponto ao final da sentença, o entrevistador se utiliza muito mais da estratégia de realce por meio da clivagem, seja para reativar o referente, seja para retomá-lo, uma vez que processou a pergunta numa ordem invertida ou faz reparos de processamento ao lançá-la.

(23) E- É qual e- para você qual foi o maior jogador de futebol do Brasil? Vamos ver você concorda comigo! [pequeno silencio] 
A função pragmática de qual que $X$ fica clara em alguns trechos da entrevista como em:

(24) E- Qual [ruído] que a senhora prefere fazer?

F- Ah! Lá em casa faço assim: macarronada, nhoque, [est] quando tem gente, não é? Assim- [o]- o peixe com creme de leite, com a ... camarão, tudo no forno, não é?

Muitos aspectos envolvidos no processo de focalização examinado neste artigo foram deixados de lado. O fenômeno é muito mais abrangente comparativamente ao microcosmo que tivemos que focalizar para fins do estudo. Vale ainda assinalar que, embora todos os entrevistadores possuam nível superior, os empregos de interrogativas- $Q$ dos entrevistadores são sempre com clivagem no discurso indireto e a clivagem é ausente nas perguntas abertas.

Isso induz a supor que:

(a) a escolarização não é vetor decisivo para a eliminação da clivagem, como atestado para os falantes entrevistados;

(b) a funcionalidade da clivagem como estratégia de atenuação e de focalização é mais forte que a pressão da escolarização; e

(c) o estatuto cognitivo e pragmático da clivagem é inconteste.

Ademais, pode-se postular a existência de um contínuo de construçôes interrogativas com traços plenos qual $X$, que pode ainda receber reforço por meio da clivagem qual que $X$ (sem a cópula) e que chega ao polo oposto com a forma qualé, ressemantizada, cujo sentido já está praticamente desprovido dos traços genuínos de interrogação. Por isso, a clivagem opera em muitos contextos como mecanismo de esquiva do emprego da expressão qual é, esvaziada dos traços interrogativos de que se origina.

\section{Algumas considerações}

Confirmei, com esta pesquisa, que a Sociolinguística parte de premissas segundo as quais as línguas são dinâmicas e é possível descrever a regularidade dos usos variáveis das línguas. Dessa forma, ficou claro que os empregos alternantes são motivados, por isso não se pode afirmar que ocorrem por acaso. 
Procurei explicitar que a pesquisa sobre variação e mudança linguística requer o domínio de várias técnicas cujo objetivo é o de assegurar ao pesquisador argumentos sólidos e suficientes para afirmar o grau de estabilidade e de mutabilidade de um dado processo variável. Identificar regras variáveis, suas motivações de usos e atestar a pertinência de variáveis sistêmicas e não sistêmicas pressupõe percorrer um caminho espinhoso que exige cuidado e preparo por parte do pesquisador.

A complexidade do sistema da interrogação nas línguas do mundo (e em português mais especificamente) me permitiu mostrar a dificuldade de se estimar o nível de implementação de um processo variável na língua tanto quanto os efeitos de possíveis fatores propulsores e refreadores. Propiciou-me ainda distinguir quando a mudança incide no indivíduo e quando a mudança incide na comunidade. No estudo em questão, a mudança se dá no indivíduo mediante condições especiais de letramento em contraposição à estabilidade atestada no sistema do Português.

\section{Referências}

ALEXANDRE, Nelida. Estruturas em movimento: alguns tópicos sobre as construçôes-Q e de clivagem. Letras de Hoje, Porto Alegre, v. 41, n. 1, p. 99-119, mar. 2006.

BRAGA, Maria Luiza. Construções clivadas no Português do Brasil sob um enfoque funcionalista. (Mimeo a)

BRAGA, Maria Luiza. Construções clivada "em foco": clivadas, construções "E QUE” e construções que no português do Brasil. (Mimeo b)

BRAGA, Maria Luiza; KATO, Mary Azawa; MIOTO, Carlos. As construçōes-Q no português brasileiro falado: relativas, clivadas e interrogativas. KATO, Mary Azawa; NASCIMENTO, Milton do (Org.). Gramática do português culto falado no Brasil A construção da sentença. Campinas: Editora da UNICAMP, 2009. V. III. Cap. 5. FARIA, Isabel Hub; PEDRO, Emília Ribeiro; DUARTE, Inês; GOUVEIA, Carlos. Introdução à Linguística Geral Portuguesa. Lisboa: Editorial Caminho, 1996.

GROLLA, Elaine Bicudo. A aquisição de periferia esquerda da sentença em Português Brasileiro. Instituto de Estudos da Linguagem: UNICAMP, 2000. 106p.

LABOV, William. The logic of non-standard English. Languages and Linguistics Monografics, n. 22, 1969. 
LABOV, William. Sociolinguistic Patterns. Philadelphia: University Pennsylvania, 1972.

LABOV, William. Principles of linguistics changes. v. 1: internal factors. Cambrigde: Blackwell, 1994. p. 2-27.

PERGUNTAS DE CONSTITUINTE (WH) em Caboverdiano: Evidências de Foco. Disponível em: <http://www.fflch.usp.br/dlcv/lport/pdf/Oliveira_Souza2009>. Acesso em: 26 jun. 2012.

PERINI, Mário. Gramática do Português Brasileiro. São Paulo: Parábola Editorial, 2010.

PEZZATI, Erotilde Goreti; FONTES, Michel Gustavo. As interrogativas de conteúdo nas variedades do português falado. Disponível em: <gel.org.br/ detalheResumo. php?trabalho=8692>. Acesso em: 14 jul. 2012.

ROCHA LIMA, Carlos Henrique da. Gramática Normativa da Lingua Portuguesa: prefácio de Serafim da Silva Neto. 45. ed. Rio de Janeiro: José Olympio, 2006.

SILVEIRA, Victor Luiz da. A emergência de estruturas A-Barra no contexto da aquisição do Português Brasileiro como língua materna. 126 f. 2011. Tese (Doutorado) - UFRJ, Rio de Janeiro, 2011. 